\title{
ANALISIS PEMANTAUAN LAN MENGGUNAKAN METODE QoS DAN PENGKLASIFIKASIAN STATUS JARINGAN INTERNET MENGGUNAKAN ALGORITMA NAIVE BAYES
}

\author{
Sachin Sabloak ${ }^{1}$, Jasuandi Wijaya ${ }^{2}$, Abdul Rahman ${ }^{3}$, Molavi Arman ${ }^{4}$ \\ ${ }^{1,2}$ STMIK GI MDP, ${ }^{3,4}$ AMIK MDP \\ ${ }^{1,2}$ Program Studi Teknik Informatika, ${ }^{3}$ Teknik Komputer, ${ }^{4}$ Manajemen Informatika \\ Jalan Rajawali No.14, Palembang, Sumatera Selatan \\ email: ${ }^{1}$ sachin@ @ms.mdp.ac.id, ${ }^{2}$ wandii @ mhs.mdp.ac.id, ${ }^{3}$ arahman@mdp.ac.id, ${ }^{4}$ molaviarman @ gmail.com
}

\begin{abstract}
Abstrak
Pentingnya jaringan komputer pada kehidupan sekarang, perlu adanya kestabilan jaringan komputer yang digunakan. Pemantauan kualitas jaringan internet didalam sebuah jaringan LAN dilakukan network administrator untuk mendapatkan nilai dari data yang didapat, penelitian ini menerapkan algoritma Naive Bayes menggunakan dataset TIPHON dengan parameter yang terdapat dalam metode QoS yaitu delay, packetloss dan jitter untuk memonitor kualitas jaringan internet. Metode QoS akan menghasilkan nilai dari setiap parameter yang dibutuhkan untuk pemantauan jaringan, guna mendapatkan kesimpulan mengenai status jaringan internet digunakan Algoritma Naive Bayes. Metode Quality of Service (QoS) merupakan sebuah metode yang digunakan dalam mendefinisikan kemampuan suatu jaringan yang digunakan untuk pengukuran tentang kualitas jaringan. Penggunaan algoritma Naive Bayes diperlukan karena algoritma tersebut digunakan dalam pengklasifikasian yang menggunakan probabilitas dan statistik serta mampu mengambil keputusan dengan menggunakan dataset yang telah disediakan. Tujuan penelitian ini dilakukan untuk mengetahui status jaringan internet di lab komputer STMIK Global Informatika MDP serta mengetahui tingkat akurasi dari algoritma Naive Bayes untuk mengklasifikasikan status jaringan internet. Pengujian penelitian dilakukan di lab komputer STMIK Global Informatika MDP. Hasil pengujian dalam penelitian ini menunjukkan bahwa akurasi Naive Bayes yang didapatkan sebesar 87,78\% dan status jaringan internet di lab komputer STMIK Global Informatika MDP masuk ke dalam kategori memuaskan dengan nilai dominan yaitu sebesar $47,78 \%$.
\end{abstract}

Kata Kunci: Naive Bayes, network administrator, Quality of Service (QoS), status jaringan internet.

\begin{abstract}
Since computer network is very important nowadays, it needs the stability of the network used. Monitoring the quality of the internet network in LAN is conducted by an administrator to get the value of the data obtained. This research applied Naive Bayes algorithm using TIPHON data set with parameters in QoS method; delay, packetloss and jitter, to monitor the quality of the internet network. QoS method will gain value in every parameter needed for network monitoring. To get a conclusion about the status of the internet network, Naive Bayes algorithm was used. Quality of Service (QoS) method is a method used to define the ability of a network to measure its quality. Naive Bayes algorithm is needed since the algorithm is used in classifying using probability and statistic as well as making decision using dataset provided. This research is conducted to see the status of the internet network in STMIK Global Informatika $M D P$ computer laboratory and to know the level of accuracy of Naive Bayes algorithm to classify the status of the network. The research was conducted in STMIK Global Informatika MDP computer laboratory. The result of the research showed that the accuracy of Naive Bayes was $87,78 \%$ and the status of the internet network STMIK Global Informatika $M D P$ was in the category of satisfactory with dominant value 47,78\%.
\end{abstract}

Keywords: internet network status, Naive Bayes, network administrator, Quality of Service (QoS) 


\section{Pendahuluan}

Pentingnya jaringan komputer pada kehidupan sekarang, perlu adanya kestabilan jaringan komputer yang digunakan. Disinilah seorang network administrator jaringan memposisikan diri menjaga stabilitas jaringan komputer. Monitoring Jaringan Komputer adalah metode utama untuk menjaga stabilitas jaringan komputer. Dengan monitoring diharapkan jika terjadi permasalahan pada jaringan dapat diperbaiki dengan cepat dan mudah oleh administrator. Pemantauan kualitas jaringan dibutuhkan beberapa parameter seperti throughput, delay, jitter, bandwidth dan packetloss (Sri Uta, i Intan Wjaya, D. A. K. M. E. D, 2015).. Metode Quality of Service (Qos) memiliki parameterparameter yang dibutuhkan untuk pemantauan jaringan dan telah ditetapkan dalam standar indeks dan kategori untuk masing-masing parameter.

Beberapa penelitian Metode QoS untuk pemantauan status jaringan internet yaitu menggunakan parameter Delay, Jitter, PacketLoss dan Throughput yang mendapatkan hasil sangat memuaskan untuk gedung laboratorium dan memuaskan untuk gedung yang lainnya (Wulandari, R, 2016). Menggunakan parameter Delay, Jitter, PacketLoss dan Throughput yang mendapatkan hasil memuaskan untuk 3 gedung yang diteliti (Pinem, R. S. L. d. M, 2014). Menggunakan parameter Delay, Bandwith dan PacketLoss yang mendapatkan hasil sedang untuk 4 gedung yang diteliti (Ramadhan, H., Saputra, E., and Fronita, M, 2016).

Metode QoS akan menghasilkan nilai dari setiap parameter yang dibutuhkan untuk pemantauan jaringan, guna mendapatkan kesimpulan mengenai status jaringan internet digunakan Algoritma Naive Bayes yang mampu mengambil keputusan dengan menggunakan dataset yang telah disediakan.

Beberapa penelitian Algoritma Naive Bayes dalam data classifier memiliki tingkat akurasi yang tinggi yaitu menunjukkan bahwa Naive Bayes memiliki tingkat akurasi sebesar $76.30 \%$ sedangkan J48 memiliki tingkat akurasi $73.82 \%$ dalam mengklasifikasikan menggunakan dataset diabetes (Joshi, S., Pandey, B., and Joshi, N, 2015). Menunjukkan bahwa Naive Bayes memiliki tingkat akurasi sebesar $76.95 \%$, J48 memiliki tingkat akurasi $76.52 \%$ sedangkan RBF memiliki tingkat akurasi 74.34\% dalam diagnosis diabetes tipe II (Sa'di, S., Maleki, A., Hashemi, R., Panbechi, Z., and Chalabi, $\mathrm{K}$, 2015). Menunjukkan bahwa Algoritma Naive
Bayes memiliki tingkat akurasi sebesar $92.34 \%$ dalam klasifikasi terhadap data capture traffic jaringan (Dibawan, I. M. B., Widyantara, I. M. O., and Linawati, 2016). Menunjukkan bahwa Algoritma Naive Bayes memiliki tingkat akurasi sebesar $93.2 \%$ dalam klasifikasi status gizi (Kusumadewi, S. 2009).

Hasil yang diharapkan dalam menggabungkan metode QoS dan Algoritma Naïve Bayes adalah untuk metode QoS untuk mengolah data dari parameter yang digunakan sedangkan algoritma Naive Bayes untuk mengklasifikasikan status jaringan internet pada lab komputer agar dapat mengetahui status jaringan internet pada lab komputer STMIK Global Informatika MDP.

\section{KAJIAN LITERATUR}

\section{II.1 Quality Of Service (QoS)}

Quality of Service (QoS) merupakan metode pengukuran tentang kualitas jaringan dan merupakan suatu usaha untuk mendefinisikan karakteristik dan sifat dari suatu jaringan. Pengguna menentukan persyaratan kinerjanya berupa parameter Quality of Service seperti delay atau packetloss, dan jaringan melakukan penggunaan bandwidth untuk skema QoS yang berbeda untuk memenuhi permintaan (Bobanto, W. S., Lumenta, A. S. M., and Najoan, X, 2014). Tabel 1 merupakan standarisasi hasil untuk parameter QoS.

Tabel 1: Standarisasi QoS (TIPHON)

\begin{tabular}{ccc}
\hline \hline Nilai & Persentase & Indeks \\
\hline \hline $3,8-4$ & $95-100 \%$ & Sangat Memuaskan \\
$3-3,79$ & $75-95 \%$ & Memuaskan \\
$2-2,99$ & $50-75 \%$ & Kurang Memuaskan \\
$1-1,99$ & $25-50 \%$ & Jelek \\
\hline \hline
\end{tabular}

\section{II.2 Parameter Parameter Quality of Service (QoS)}

Quality of Service memiliki beberapa parameter yang digunakan untuk mengetahui status jaringan. Parameter-parameter Quality of Service tersebut terdiri dari bandwidth, delay, jitter, throughput, dan packetloss (Bobanto, W. S., Lumenta, A. S. M., and Najoan, X, 2014). Berikut adalah penjelasan singkat dari parameter Quality of Service:

\section{II.2.1 Bandwidth}

Bandwidth adalah luas atau lebar cakupan frekuensi yang digunakan oleh sinyal dalam medium 
transmisi. Frekuensi sinyal di ukur dalam satuan Hertz $(\mathrm{Hz})$. Di dalam jaringan komputer, bandwidth sering digunakan sebagai suatu persamaan untuk mengukur kecepatan transfer data (transfer rate) yaitu jumlah data yang dapat dibawa dari sebuah titik ke titik lain dalam jangka waktu tertentu (pada umunya dalam detik). Jenis bandwidth ini biasanya diukur dalam bit per second(bps) (Bobanto, W. S., Lumenta, A. S. M., and Najoan, X, 2014).

\section{II.2.2 Delay}

Delay adalah jeda waktu antara paket data yang dikirim dan respon paket data yang di terima atau waktu yang dibutuhkan untuk mengirimkan data dari terminal sumber sampai terminal tujuan (Bobanto, W. S., Lumenta, A. S. M., and Najoan, X, 2014).. Tabel 2 merupakan standarisasi Delay berdasarkan standarisasi TIPHON.

Tabel 2 Tabel Standarisasi Delay (TIPHON)

\begin{tabular}{ccc}
\hline \hline Ketegori Delay & Besar Delay & Indeks \\
\hline \hline Sangat Bagus & $<150 \mathrm{~ms}$ & 4 \\
Bagus & $<250 \mathrm{~ms}$ & 3 \\
Sedang & $<350 \mathrm{~ms}$ & 2 \\
Jelek & $<450 \mathrm{~ms}$ & 1 \\
\hline \hline
\end{tabular}

Penulisan rumus (TIPHON) :

Persamaan Delay :

Delay $=$ Waktu Paket Diterima - Waktu Paket

Dikirim ... [1]

\section{II.2.3 Jitter}

Jitter adalah variasi delay yang terjadi akibat adanya selisih waktu atau interval antar kedatangan paket di penerima. Untuk mengatasi jitter maka paket data yang datang dikumpulkan dulu dalam jitter buffer selama waktu yang telah ditentukan sampai paket dapat diterima pada sisi penerima dengan urutan yang benar (Bobanto, W. S., Lumenta, A. S. M., and Najoan, X, 2014). Tabel 3 merupakan standarisasi Jitter berdasarkan standarisasi TIPHON.
Tabel 3 Tabel Standarisasi Jitter (TIPHON)

\begin{tabular}{ccc}
\hline \hline Ketegori Jitter & Jitter & Indeks \\
\hline \hline Sangat Bagus & $0 \mathrm{~ms}$ & 4 \\
Bagus & $75 \mathrm{~ms}$ & 3 \\
Sedang & $125 \mathrm{~ms}$ & 2 \\
Jelek & $225 \mathrm{~ms}$ & 1 \\
\hline \hline
\end{tabular}

Penulisan rumus (TIPHON) :

Pesamaan Jitter :

Jitter $=$ Delay $-($ Rata-rata Delay $)$

\section{II.2.4 Packetloss}

Packetloss adalah persentase jumlah data yang gagal dikirim. Diakibatkan karena kemacetan transmisi paket akibat padatnya traffic yang harus dilayani (Bobanto, W. S., Lumenta, A. S. M., and Najoan, X, 2014). Tabel 4 merupakan standarisasi PacketLoss berdasarkan standarisasi TIPHON

Tabel 4 Tabel Standarisasi Packetloss (TIPHON)

\begin{tabular}{ccc}
\hline \hline $\begin{array}{c}\text { Ketegori } \\
\text { Packetloss }\end{array}$ & Packetloss & Indeks \\
\hline \hline Sangat Bagus & $0 \%$ & 4 \\
Bagus & $3 \%$ & 3 \\
Sedang & $15 \%$ & 2 \\
Jelek & $25 \%$ & 1 \\
\hline \hline
\end{tabular}

Penulisan rumus (TIPHON) :

Perhitungan Packetloss:

Packetloss $=$ data dikirim - data diterima $\times 100 \%$

Paket data dikirim $\quad \ldots[3]$

\section{II.2.5 Throughput}

Throughput adalah jumlah data yang dikirim oleh jaringan atau entitas menerima data, atau jumlah data yang diproses dalam satu ruang waktu yang ditentukan (TIPHON, 1999). 


\section{II.3 Naive Bayes}

Algoritma Naive Bayes adalah algoritma yang mampu memprediksi peluang di masa depan berdasarkan pengalaman di masa sebelumnya dengan menggunakan metode probabilitas dan statistik (Saleh, A, 2015).

Rumus yang digunakan pada algoritma Naive Bayes adalah sebagai berikut :

Penulisan rumus (Saleh, A, 2015):

$$
\begin{gathered}
\mathrm{P}(\mathrm{H} \mid \mathrm{X})=\frac{\mathrm{P}(\mathrm{X} \mid \mathrm{H})}{\mathrm{P}(\mathrm{X})} \\
P(c \mid \mathrm{X})=P\left(x_{1} \mid c\right) \times P\left(x_{2} \mid c\right) \times \cdots \times P\left(x_{n} \mid c\right) \times P(c)
\end{gathered}
$$

Di mana :

$$
\begin{array}{cl}
\mathrm{X}: & \begin{array}{l}
\text { Data dengan class yang belum diketahui. } \\
\mathrm{H}:
\end{array} \\
\mathrm{l} & \begin{array}{l}
\text { Hipotesis data merupakan suatu class } \\
\text { spesifik. }
\end{array} \\
\mathrm{P}(\mathrm{H} \mid \mathrm{X}): & \begin{array}{l}
\text { Probabilitas hipotesis } \mathrm{H} \text { berdasar kondisi } \mathrm{X} \\
\text { (posteriori probabilitas) }
\end{array} \\
\mathrm{P}(\mathrm{H}): & \text { Probabilitas hipotesis } \mathrm{H} \text { (prior probabilitas) } \\
\mathrm{P}(\mathrm{X} \mid \mathrm{H}): & \begin{array}{l}
\text { Probabilitas } \mathrm{X} \text { berdasarkan kondisi pada } \\
\text { hipotesis } \mathrm{H}
\end{array} \\
\mathrm{P}(\mathrm{X}): & \text { Probabilitas } \mathrm{X}
\end{array}
$$

Agar mampu mengerti megenai Algoritma Naive Bayes, perlu diketahui bahwa diperlukan beberapa petunjuk guna mengetahui kelas apa yang cocok bagi parameter yang akan dianalisis untuk melakukan proses klasifikasi. Oleh karena itu, penyesuaian dilakukan terhadap Algoritma Naive Bayes seperti pada persamaan Persamaan 5.

$$
\mathrm{P}(\mathrm{C} \mid \mathrm{F} 1 \ldots \mathrm{Fn})=\frac{\mathrm{P}(\mathrm{C} \mid \mathrm{F} 1 \ldots \mathrm{Fn})}{\mathrm{P}(\mathrm{C} \mid \mathrm{F} 1 \ldots \mathrm{Fn})}
$$

Varibel $\mathrm{C}$ pada Persamaan 2.6 dapat digunakan untuk mewakili kelas, sedangkan variabel $\mathrm{F} 1 \quad \ldots \quad$ Fn digunakan untuk mewakili karakteristik petunjuk yang merupakan bagian penting guna melakukan klasifikasi. Dari persamaan dapat diartikan bahwa kemungkinan masukya sampel karakteristik tertentu pada kelas C (Posterior) adalah kemungkinan munculnya Kelas C (seringkali disebut prior, karena belum masuk sampel yang baru), dikalikan dengan kemungkinan munculnya karakteristik-karakteristik sampel dalam kelas C(dapat dikatakan likehood) ,dibagi dengan kemungkinan munculnya karakteristik-karakteristik contoh secara global (dapat dikatakan evidence). Dari penjelasan diatas, Persamaan 5 dapat dijelaskan secara sederhana seperti pada Persamaan 6 :

Posterior $=\frac{\text { prior } \times \text { likelihood }}{\text { evidence }}$

Karakteristik-karakteristik sampel secara global atau disebut juga evidence pada satu sampel selalu tetap untuk setiap kelas. Nilai dari posterior pada akhirnya dibandingkan dengan nilai posterior pada kelas lain guna membantu menentukan ke kelas apa suatu sampel akan digolongkan. Penjelasan mengenai rumus Bayes dapat dilakukan dengan cara menjabarkan $(\mathrm{C} \mid \mathrm{F} 1, \ldots$,$) lebih rinci mengikuti aturan$ perkalian sebagai berikut [Saleh, 2015]:

$\mathrm{P}(\mathrm{C} \mid \mathrm{F} 1, \ldots, \mathrm{Fn})=\mathrm{P}(\mathrm{C}) \mathrm{P}(\mathrm{F} 1, \ldots, \mathrm{Fn} \mid \mathrm{C})$

$=\mathrm{P}(\mathrm{C}) \mathrm{P}(\mathrm{F} 1 \mid \mathrm{C}) \mathrm{P}(\mathrm{F} 2, \ldots, \mathrm{Fn} \mid \mathrm{C}, \mathrm{F} 1)$

$=\mathrm{P}(\mathrm{C}) \mathrm{P}(\mathrm{F} 1 \mid \mathrm{C}) \mathrm{P}(\mathrm{F} 2 \mid \mathrm{C}, \mathrm{F} 1) \mathrm{P}(\mathrm{F} 3, \ldots, \mathrm{Fn} \mid \mathrm{C}, \mathrm{F} 1, \mathrm{~F} 2)$

$=(\mathrm{C}) \mathrm{P}(\mathrm{F} 1 \mid \mathrm{C}) \mathrm{P}(\mathrm{F} 2 \mid \mathrm{C}, \mathrm{F} 1) \mathrm{P}(\mathrm{F} 3 \mid \mathrm{C}, \mathrm{F} 1, \mathrm{~F} 2)$

$\mathrm{P}(\mathrm{F} 4, \ldots, \mathrm{Fn} \mid \mathrm{C}, \mathrm{F} 1, \mathrm{~F} 2, \mathrm{~F} 3)$

$=\mathrm{P}(\mathrm{C}) \mathrm{P}(\mathrm{F} 1 \mid \mathrm{C})$

$\mathrm{P}(\mathrm{F} 2 \mid \mathrm{C}, \mathrm{F} 1) \mathrm{P}(\mathrm{F} 3 \mid \mathrm{C}, \mathrm{F} 1, \mathrm{~F} 2) \ldots \mathrm{P}(\mathrm{Fn} \mid \mathrm{C}, \mathrm{F} 1, \mathrm{~F} 2, \mathrm{~F} 3, \ldots, \mathrm{Fn}-1)$

Dari penjabaran di atas maka diketahuilah bahwa hasil dari penjabaran tersebut menyebabkan semakin panjang dan semakin rumitnya faktor-faktor yang mempengaruhi nilai probabilitas, yang menyebabkan hamper tidak mungkin faktor tersebut untuk dianalisa satu per satu. Dampak dari penjabaran tersebut maka perhitungan Bayes menjadi sulit untuk dilakukan. Pada bagian ini digunakanlah naif (asumsi independensi yang sangat tinggi), bahwa setiap petunjuk (F1,F2...Fn) independen atau tidak ada keterkaitan antara satu sama lain. Dari penjelasan diatas, maka digunakanlah kesamaan seperti pada Persamaan 7 [Saleh, 2015]:

$$
\mathrm{P}(\mathrm{Fi} \mid \mathrm{Fj}) \frac{\mathrm{P}(\mathrm{Fi} \cap F \mathrm{f})}{\mathrm{P}(\mathrm{Fj})}=\mathrm{P}(\mathrm{Fi}) \mathrm{P}(\mathrm{Fj}) \mathrm{P}(\mathrm{Fj})=\mathrm{P}(\mathrm{Fi})
$$

Untuk i $6 \neq \mathrm{j}$, sehingga

$\mathrm{P}(\mathrm{Fi} \mid \mathrm{C}, \mathrm{Fj})=\mathrm{P}(\mathrm{Fi} \mid \mathrm{C})$

Berdasarkan Persamaan 7 dan Persamaan 8 dapat dilihat sebuah persamaan yang merupakan model dari teorema Naive Bayes yang dapat digunakan untuk melakukan proses klasifikasi. Apabila data yang 
digunakan untuk klasifikasi adalah data kontinyu maka berlakulah rumus Densitas Gauss seperti pada Persamaan 9

$P\left(X_{i}=x_{i} \mid Y_{i}=y_{i}\right)=\frac{1}{\sqrt{2 \mu \alpha_{i j}}} e^{\frac{-\left(x_{i}-\mu_{i j}\right)^{2}}{2 \alpha_{i j}^{2}}}$

Di mana :

$\mathrm{P}:$ Peluang

$\mathrm{Xi}$ : Atribut ke i

xi : Nilai atribut ke i

$\mathrm{Y}$ : Kelas yang dicari

yi : Subkelas Y yang dicari

$\mu$ : mean, menyatakan rata-rata dari seluruh atribut

$\alpha$ : Deviasi standar, menyatakan varian dari seluruh atribut.

Alur penjelasan dari Algoritma Naive Bayes dapat dilihat pada Gambar 2 sebagai berikut [Saleh, 2015]:

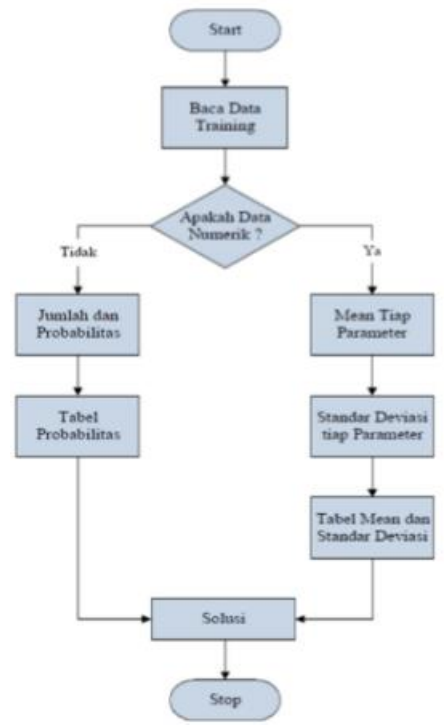

Gambar 1. Alur Metode Naive Bayes [Saleh, 2015]

\section{II.4 Topologi Jaringan Yang Digunakan}

Jaringan komputer tidak lepas dari topologi. Topologi jaringan komputer adalah usunan atau pemetaan interkoneksi antara node, dari suatu jaringan, baik secara fisik (riil) dan logis (virtual) atau pula dapat dikatakan sebagai infrastruktur fisik jaringan komputer yang digunakan untuk mengimplementasikan Local Area Network. Topologi jaringan yang digunakan adalah topologi star. Topologi star merupakan topologi yang banyak digunakan diberbagai tempat, karena kemudahan untuk menambah, mengurangi, atau mendeteksi kerusakan jaringan yang ada. Topologi star menggunakan hub atau switch dalam mengatur paket data dan setiap node berkomunikasi langsung dengan central node yang dapat dilihat seperti pada Gambar 1 (Wulandari, R, 2016).

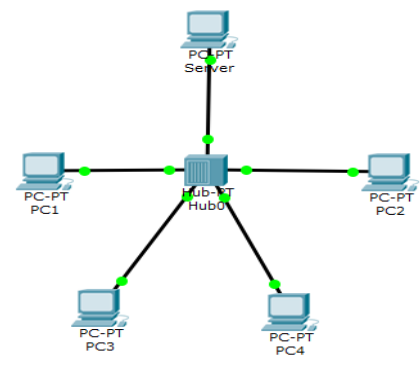

Gambar 2 Topologi Star

\section{Pembahasan Dan Hasil}

\section{III.1 Pengambilan data}

Gambar 3 merupakan pengujian secara langsung di lab komputer STMIK Global Informatika MDP. Pengujian yang dilakukan adalah pengujian jaringan internet pada lab komputer dan data-data yang akan diambil sesuai dengan parameter yang telah ditetapkan yaitu data delay, jitter dan packetloss. Pengujian akan dilakukan dengan cara mengirimkan ping sesuai dengan limit yang telah ditentukan ke google.com

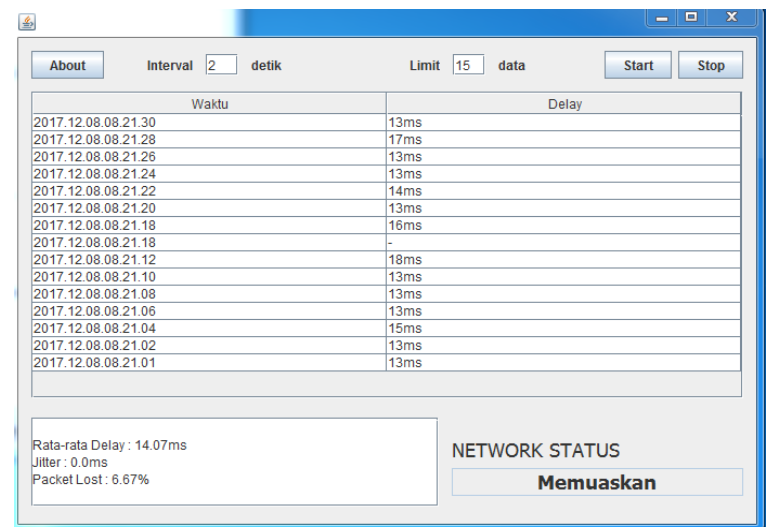

Gambar 3 Pengujian

III.1.1 Delay

Sachin Sabloak, Jasuandi Wijaya, Abdul Rahman, Molavi Arman 
Gambar 2 merupakan pengujian yang telah dilakukan dimana aplikasi melakukan monitoring jaringan internet dengan cara mengirim ping ke google.com pada lab komputer STMIK Global Infomatika MDP dengan rentang interval selama $2 \mathrm{~s}$ dan limit sebanyak 15 kali pengiriman. Untuk melakukan perhitungan rata-rata delay menggunakan aplikasi dapat dilihat dari banyaknya ping yang diterima dan jumlah dari besarnya delay sebanyak ping yang diterima. Dapat dilihat banyaknya ping yang diterima adalah sebanyak 14 pengiriman dari 15 kali pengiriman. Maka akan didapatkan total rata-rata delay sebagai berikut :

$=(13 \mathrm{~ms}+13 \mathrm{~ms}+15 \mathrm{~ms}+13 \mathrm{~ms}+13 \mathrm{~ms}+13 \mathrm{~ms}+$ $18 \mathrm{~ms}+16 \mathrm{~ms}+13 \mathrm{~ms}+14 \mathrm{~ms}+13 \mathrm{~ms}+13 \mathrm{~ms}+$ $17 \mathrm{~ms}+13 \mathrm{~ms}) / 14$

$=197 \mathrm{~ms} / 14$

$=14,07 \mathrm{~ms}$

Berdasarkan pengujian yang telah dilakukan didapatkan total rata-rata delay sebesar 14,07 ms yang apabila dilihat berdasarkan Tabel 2 maka akan masuk kedalam kategori Sangat Bagus.

\section{III.1.2 Perhitungan Jitter}

Untuk melakukan perhitungan jitter perlu diketahui delay dan rata-rata delay. Dari Gambar 2 dapat dilihat bahwa nilai delay terakhir sebesar $13 \mathrm{~ms}$ dan rata-rata delay sebesar 14,07 ms, Dengan persamaan jitter maka didapat :

$=13 \mathrm{~ms}-14,53 \mathrm{~ms}$

$=-1,07 \mathrm{~ms}$

$=0 \mathrm{~ms}$

Berdasarkan pengujian yang telah dilakukan didapatkan jitter sebesar - 1,07 ms, jitter tidak bisa bernilai negatif dikarenakan nilai terendah jitter adalah $0 \mathrm{~ms}$ oleh karena itu didapatkan jitter yang bernilai $0 \mathrm{~ms}$ yang apabila dilihat berdasarkan Tabel 3 maka akan masuk kedalam kategori Sangat Bagus.

\section{III.1.3 Perhitungan Packetloss}

Untuk melakukan perhitungan PacketLoss perlu diketahui jumlah paket data yang dikirim dan jumlah paket data yang diterima. Dari Gambar 2 dapat dilihat jumlah paket yang dikirim adalah sebanyak 15 kali pengiriman ping sedangkan jumlah paket data yang diterima adalah sebanyak 14 kali, maka akan didapatkan packetloss sebagai berikut :

$=((15$ packet -14 packet $) / 15$ packet $) \times 100 \%$

$=(1$ packet $/ 15$ packet $) \times 100 \%$

$=6,67 \%$
Berdasarkan pengujian yang telah dilakukan didapatkan PacketLoss sebesar 6,67 \% yang apabila dilihat berdasarkan Tabel 4 maka akan masuk kedalam kategori Bagus.

\section{III.1.4 Naïve Bayes}

Algoritma Naive Bayes akan melakukan proses pengklasifikasian menggunakan dataset yang telah disediakan. Setelah didapatkan nilai dari setiap perhitungan parameter, maka algoritma Naive Bayes akan melakukan proses pengklasifikasian. Setelah didapatkan hasil dari parameter yaitu setelah didapat rata-rata Delay sebesar 14,07 ms, Jitter sebesar $0 \mathrm{~ms}$ dan Packetloss sebesar 6,67\%, Naive Bayes akan melakukan pengklasifikasian bahwa jika kondisi seperti hasil pengujian diatas masuk kategori manakah status jaringan internetnya, perhitungan lebih rinci dapat dilihat sebagai berikut :

1. Untuk probabilitas hasil Sangat Memuaskan $(\mathrm{H}=3,8-4)$

$\mathrm{p}(\mathrm{H}=3,8$ - 4) $\mathrm{p}(\mathrm{H}=3,8-4 \mathrm{jD}<150 \mathrm{~ms}) \mathrm{p}(\mathrm{H}=3,8-$ $4 \mathrm{jJ}=0-75 \mathrm{~ms}) \mathrm{p}(\mathrm{H}=3,8-4 \mathrm{jP}=3 \%-15 \%)$

$=(0,016)(1)(1)(0)$

$=0$

2. Untuk probabilitas hasil Memuaskan ( $\mathrm{H}=3$ $3,79)$

$\mathrm{p}(\mathrm{H}=3-3,79) \mathrm{p}(\mathrm{H}=3-3,79 \mathrm{jD}<150 \mathrm{~ms}) \mathrm{p}(\mathrm{H}=3-$ $3,79 \mathrm{jJ}=0-75 \mathrm{~ms}) \mathrm{p}(\mathrm{H}=3-3,79 \mathrm{jP}=3 \%-$ $15 \%)$

$=(0,297)(0,474)(0,474)(0,316)$

$=0,021$

3. Untuk probabilitas hasil Kurang Memuaskan $(\mathrm{H}=2-2,99)$

$\mathrm{p}(\mathrm{H}=2-2,99) \mathrm{p}(\mathrm{H}=2-2,99 \mathrm{jD}=<150 \mathrm{~ms}) \mathrm{p}(\mathrm{H}=2-$ $2,99 \mathrm{jJ}=0-75 \mathrm{~ms}) \mathrm{p}(\mathrm{H}=2-2,99 \mathrm{jP}=3 \%-$ $15 \%)$

$=(0,531)(0,176)(0,176)(0,265)$

$=0,004$

4. Untuk probabilitas hasil Jelek $(\mathrm{H}=1-1,99)$

$\mathrm{p}(\mathrm{H}=1-1,99) \mathrm{p}(\mathrm{H}=1-1,99 \mathrm{jD}=<150 \mathrm{~ms}) \mathrm{p}(\mathrm{H}=1-$ $1,99 \mathrm{jJ}=0-75 \mathrm{~ms}) \mathrm{p}(\mathrm{H}=1-1,99 \mathrm{jP}=3 \%-$ $15 \%)$

$=(0,156)(0)(0)(0,1)$

$=0$

5. Hasil Pengklasifikasian

$=\operatorname{argmax} \mathrm{p}($ Sangat Memuaskan $) \cdot \mathrm{p}($ Memuaskan $)$. $\mathrm{p}($ Kurang Memuaskan $)$. p(Jelek)

$=\operatorname{argmax}(0)(0,021)(0,004)(0)$

$=0,021$

Sachin Sabloak, Jasuandi Wijaya, Abdul Rahman, Molavi Arman 
Jadi, didapat hasil pengklasifikasian algoritma Naive Bayes untuk klasifikasi status jaringan internet masuk ke dalam kategori "Memuaskan" dengan nilai probabilitas paling besar di bandingkan dengan yang lainnya yaitu sebesar 0,021 .

\section{III.2 Hasil Pengujian}

Tabel 5 merupakan hasil pengujian yang telah dilakukan selama 3 hari pada lab komputer STMIK Global Informatika MDP, hasil pengujian dapat dilihat sebagai berikut :

Tabel 5 Tabel Hasil Pengujian

\begin{tabular}{|c|c|c|c|c|c|}
\hline \multirow{2}{*}{$\begin{array}{c}\text { Waktu } \\
\text { Pengujian }\end{array}$} & \multirow{2}{*}{$\begin{array}{l}\text { Tanggal } \\
\text { Pengujian }\end{array}$} & \multicolumn{4}{|c|}{ Hasil Pengklasifikasian Internet } \\
\hline & & $\begin{array}{c}\text { Sangat } \\
\text { Memuaskan }\end{array}$ & Memuaskan & $\begin{array}{c}\text { Kurang } \\
\text { Memuaskan }\end{array}$ & Jelek \\
\hline \multirow[t]{3}{*}{$7: 50-9: 30$} & Senin, 5-2-2018 & 1 kali & 9kali & Okali & Okali \\
\hline & Selasa, 6-2-2018 & 1 kali & 7kali & 2kali & Okali \\
\hline & Rabu, 7-2-2018 & Okali & 7kali & $3 \mathrm{kali}$ & Okali \\
\hline \multirow[t]{3}{*}{$9: 40-11: 20$} & Senin, 5-2-2018 & 4kali & 4 kali & 2kali & Okali \\
\hline & Selasa, 6-2-2018 & Okali & 7kali & 3kali & Okali \\
\hline & Rabu, 7-2-2018 & 2kali & 7kali & 1kali & Okali \\
\hline \multirow[t]{3}{*}{$11: 30-13: 10$} & Senin, 5-2-2018 & Okali & Okali & Okali & 10kali \\
\hline & Selasa, 6-2-2018 & 10kali & Okali & 0kali & Okali \\
\hline & Rabu, 7-2-2018 & 8kali & 2kali & Okali & Okali \\
\hline
\end{tabular}

Berdasarkan pada pengujian Tabel 5 dapat diketahui waktu terbaik untuk menggunakan internet di lab komputer sebagai berikut :

* Waktu Pengujian 7:50-9:30 :

-Kategori Sangat Memuaskan :

$=((1+1+0) / 30) \times 100 \%$

$=(2 / 30) \times 100 \%$

$=6,67 \%$

-Kategori Memuaskan :

$=((9+7+7) / 30) \times 100 \%$

$=(23 / 30) \times 100 \%$

$=76,67 \%$

-Kategori Kurang Memuaskan :

$=((0+2+3) / 30) \times 100 \%$

$=(5 / 30) \times 100 \%$

$=16,67 \%$

-Kategori Jelek
$=((0+0+0) / 30) \times 100 \%$

$=(0 / 30) \times 100 \%$

$=0 \%$

* Waktu Pengujian 9:40-11:20 :

-Kategori Sangat Memuaskan :

$=((4+0+2) / 30) \times 100 \%$

$=(6 / 30) \times 100 \%$

$=20 \%$

-Kategori Memuaskan :

$=((4+7+7) / 30) \times 100 \%$

$=(18 / 30) \times 100 \%$

$=60 \%$

-Kategori Kurang Memuaskan :

$=((2+3+1) / 30) \times 100 \%$

$=(6 / 30) \times 100 \%$

$=20 \%$

Sachin Sabloak, Jasuandi Wijaya, Abdul Rahman, Molavi Arman 
-Kategori Jelek :

$=((0+0+0) / 30) \times 100 \%$

$=(0 / 30) \times 100 \%$

$=0 \%$

* Waktu Pengujian 11:30-13:10 :

-Kategori Sangat Memuaskan :

$=((0+10+8) / 30) \times 100 \%$

$=(18 / 30) \times 100 \%$

$=60 \%$

-Kategori Memuaskan :

$=((0+0+2) / 30) \times 100 \%$
$=(2 / 30) \times 100 \%$

$=6,67 \%$

-Kategori Kurang Memuaskan :

$=((0+0+0) / 30) \times 100 \%$

$=(0 / 30) \times 100 \%$

$=0 \%$

-Kategori Jelek :

$=((10+0+0) / 30) \times 100 \%$

$=(10 / 30) \times 100 \%$

$=33,33 \%$

Tabel 6 Tabel Hasil

\begin{tabular}{ccccc}
\hline \hline Waktu Pengujian & \multicolumn{3}{c}{ Hasil Pengklasifikasian Internet } \\
\cline { 2 - 5 } & $\begin{array}{c}\text { Sangat } \\
\text { Memuaskan }\end{array}$ & Memuaskan & $\begin{array}{c}\text { Kurang } \\
\text { Memuaskan }\end{array}$ & Jelek \\
$7: 50-9: 30$ & $6,67 \%$ & $76,67 \%$ & $16,67 \%$ & $0 \%$ \\
$9: 40-11.20$ & $20 \%$ & $60 \%$ & $20 \%$ & $0 \%$ \\
$11: 30-13: 10$ & $60 \%$ & $6,67 \%$ & $0 \%$ & $33,33 \%$ \\
\hline \hline
\end{tabular}

-Kategori Sangat Memuaskan :

Tabel 6 merupakan hasil perhitungan yang sudah $=(6,67 \%+20 \%+60 \%) / 3$ dilakukan. Berdasarkan pada pengujian Tabel 6 dapat disimpulkan bahwa waktu terbaik untuk menggunakan internet di STMIK Global Informatika MDP pada lab computer A207 adalah pada pukul 11:30-13:10 dikarenakan pada jam tersebut didapatkan hasil pengujian internet masuk ke dalam kategori Sangat Memuaskan dengan nilai tertinggi 60\% dibandingkan pada pukul 7:50-9:30 dengan nilai sebesar 6,67\% dan pada pukul 9:40-11:20 dengan nilai sebesar $20 \%$.

Berdasarkan pada pengujian Tabel 6 dapat disimpulkan bahwa waktu penggunaan internet terbanyak di STMIK Global Informatika MDP pada lab komputer A207 adalah pada pukul 9:40-11:20 dikarenakan pada jam tersebut didapatkan hasil pengujian internet masuk ke dalam kategori Kurang Memuaskan dengan nilai lebih tinggi sebesar $20 \%$ dibandingkan pada pukul 11:30-13:10 dengan nilai sebesar 0\% dan pada pukul 7:50-9:30 dengan nilai sebesar $16,67 \%$.

Berdasarkan pada pengujian Tabel 6 kondisi jaringan internet pada lab komputer STMIK Global Informatika MDP dapat disimpulkan dengan rincian $=28,89 \%$

-Kategori Memuaskan :

$=(76,67 \%+60 \%+6,67) / 3$

$=47,78 \%$

-Kategori Kurang Memuaskan :

$=(16,67 \%+20 \%+0 \%) / 3$

$=12,22 \%$

-Kategori Jelek :

$=(0 \%+0 \%+33,33 \%) / 3$

$=11,11 \%$

Jadi, berdasarkan perhitungan diatas didapat bahwa kondisi status jaringan internet di lab komputer STMIK Global Informatika MDP masuk ke dalam kategori Memuaskan dengan nilai dominan yaitu sebesar $47,78 \%$.

Tabel 7 Tingkat Akurasu Algoritma

\begin{tabular}{cc}
\hline \hline Hari & Tingkat Akurasi \\
\hline \hline Senin, 5-2-2018 & $93,33 \%$ \\
Selasa, 6-2-2018 & $83,33 \%$ \\
Rabu, 7-2-2018 & $86,67 \%$ \\
\hline \hline
\end{tabular}


Tabel 7 merupakan tingkat akurasi algoritma selama pengujian berlansung, Berdasarkan pada pengujian Tabel 7 penerapan Algoritma Naive Bayes sudah cukup bagus dengan mendapatkan tingkat akurasi $87,78 \%$ selama 3 hari dengan total 90 kali pengujian pada lab A207 dengan rincian sebagai berikut :

$$
\begin{aligned}
& =(93,33 \%+83,33 \%+86,67 \%) / 3 \\
& =263,33 \% / 3 \\
& =87,78 \%
\end{aligned}
$$

Berdasarkan pengujian yang telah dilakukan didapatkan waktu terbaik untuk menggunakan internet pada pukul 11:30-13:10 dan waktu penggunaan internet terbanyak pada pukul 9:40-11:20 di lab komputer STMIK Global Informatika MDP, serta kualitas jaringan internet di STMIK Global Informatika MDP masuk kedalam kategori Memuaskan selama pengujian berlangsung dan didapatkan tingkat akurasi dari algoritma selama pengujian adalah sebesar $87,78 \%$.

\section{KESIMPULAN DAN SARAN}

\section{IV.1 Kesimpulan}

Dari hasil penelitian dan pembahasan yang dilakukan, maka dapat disimpulkan bahwa:

1. Algoritma Naive Bayes dapat digunakan untuk mengklasifikasikan status jaringan internet berdasarkan parameter-parameter yang terdapat dalam metode QoS yaitu delay, jitter dan packetloss dengan tingkat akurasi yang dihasilkan dari 90 kali pengujian adalah sebesar $87,78 \%$.

2. Waktu terbaik untuk menggunakan internet adalah pada pukul 11:30-13:10 dan waktu penggunaan internet terbanyak pada pukul 9:40-11:20 di lab komputer STMIK Global Informatika MDP.

3. Status jaringan internet di lab komputer STMIK Global Informatika MDP masuk ke dalam kategori Memuaskan dengan nilai dominan yaitu sebesar $47,78 \%$.

\section{IV.2 Saran}

Saran yang dapat direkomendasikan untuk penelitian selanjutnya adalah:

1. Dapat diterapkan algoritma lain untuk mengklasifikasikan status jaringan internet agar didapatkan tingkat akurasi yang lebih tinggi.
2. Hasil penelitian dapat digunakan oleh bagian UPT sebagai sarana evaluasi keadaan koneksi internet di STMIK Global Informatika MDP.

\section{REFERENSI}

Sri Uta, I Intan Wjaya, D. A. K. M. E. D. (2015). Monitoring Dan Analisis Kualitas Quality of Services ( Qos ) Untuk Meningkatkan Kualitas Layanan Trafik Kamera Cctv Pada Jaringan Wireless ( Studi Kasus : Pt . Indonet Di Cirebon )

Wulandari, R. (2016). Analisis Qos ( Quality Of Service) Pada Jaringan Internet ( Studi Kasus : Upt Loka Uji Teknik Penambangan Jampang Kulon Lipi ). Jurnal Teknik Informatika Dan Sistem Informasi, 2:162172.

Pinem, R. S. L. d. M. (2014). Analisis Quality of Service (QoS) Jaringan Internet di SMK Telkom Medan. Singuda Ensikom, 7(3):1

Ramadhan, H., Saputra, E., and Fronita, M. (2016). Analsis Kualitas Layanan Jaringan Internet Menggunakan Metode Rma (Realibility, Maintainability and Availability) Dan Qos (Quality of Service). Rekayasa Dan Manajemen Sistem Informasi, 2(2):56-60.

Joshi, S., Pandey, B., and Joshi, N. (2015). Comparative analysis of Naive Bayes and J48 Classification Algorithms. International Journal of Advanced Research in Computer Science and Software Engineering, 5(12):813-817.

Sa'di, S., Maleki, A., Hashemi, R., Panbechi, Z., and Chalabi, K. (2015). Comparison of Data Mining Algorithms in the Diagnosis of Type Ii Diabetes. International Journal on Computational Science \& Applications, 5(5):1-12.

Dibawan, I. M. B., Widyantara, I. M. O., And Linawati (2016). Klasifikasi Trafik Internet Kampus Berbasis. 3(2):7-14.

Kusumadewi, S. (2009). Klasifikasi Status Gizi Menggunakan Naive Bayesian

Sachin Sabloak, Jasuandi Wijaya, Abdul Rahman, Molavi Arman 
Classification. Jurnal Universitas Binus (COMMIT), 3(1):6-11.

Bobanto, W. S., Lumenta, A. S. M., and Najoan, X. (2014). Analisis Kualitas Layanan Jaringan Internet ( Studi Kasus PT . Kawanua Internetindo Manado ). jurnal Teknik Elektro dan Komputer, 1(1):80-87.

TIPHON (1999). Telecommunication and Internet Protocol Harmonization Over Network (TIPHON); General Aspects of Quality of Service (Qos).Etsi, 2.1.1:1-37.

Saleh, A. (2015). Implementasi Metode Klasifikasi Na"1ve Bayes dalam Memprediksi Besarnya Penggunaan Listrik Rumah Tangga. Citec Journal,2(3):207-217. 